\title{
Surface Hardening of Ti-15V-3Al-3Cr-3Sn Alloy after Cyclic Hydrogenation and Subsequent Solution Treatment
}

\author{
Chia-Po Hung, ${ }^{1}$ Tair-I Wu, ${ }^{2}$ and Jiann-Kuo $\mathrm{Wu}^{1}$ \\ ${ }^{1}$ Institute of Materials Engineering, National Taiwan Ocean University, Keelung 20224, Taiwan \\ ${ }^{2}$ Department of Materials Engineering, Tatung University, Taipei 10451, Taiwan \\ Correspondence should be addressed to Jiann-Kuo Wu; a0055@ntou.edu.tw
}

Received 24 November 2013; Accepted 9 February 2014; Published 12 March 2014

Academic Editor: Ming-Xing Zhang

Copyright (c) 2014 Chia-Po Hung et al. This is an open access article distributed under the Creative Commons Attribution License, which permits unrestricted use, distribution, and reproduction in any medium, provided the original work is properly cited.

\begin{abstract}
The as-received and preheated $\left(1000^{\circ} \mathrm{C}-30 \mathrm{~min}\right.$. and $500^{\circ} \mathrm{C}-30 \mathrm{~min}$.) sheets of Ti-15V-3Al-3Cr-3Sn alloy (Ti-153) were treated according to the predetermined process including a cyclic electrolytic hydrogenation (at $50 \mathrm{~mA} / \mathrm{cm}^{2}$ for $1 \mathrm{hr}$ and at $5 \mathrm{~mA} / \mathrm{cm}^{2}$ for $10 \mathrm{hrs}$ ) combining a subsequent solution treatment to see the effects of various operating parameters on the evolution of microstructure and the variations of hardness. The hardening effect deriving from solid-solution strengthening of hydrogen eventually overrode that from precipitation hardening. The maximum hardness elevation was from 236.9 to $491.1 \mathrm{VHN}$.
\end{abstract}

\section{Introduction}

Titanium alloys are traditionally divided into three categories, $\alpha, \alpha+\beta$, and $\beta$ alloys, according to the stabilizing elements alloyed [1-3]. Commercial purity titanium (CP-Ti) and Ti6Al-4V (Ti-64) are examples for $\alpha$ - and $(\alpha+\beta)$-Ti alloys, respectively, while Ti-15V-3Al-3Cr-3Sn (Ti-153) alloy can be thought of as a typical $\beta$-Ti alloy.

Hydrogen induced cracking in $\alpha$ - and $(\alpha+\beta)$-Ti alloys were attributed to hydride precipitation. Fracture arising from hydride formation in the matrix has not been reported for $\beta$-Ti alloys. The hydrogen embrittlement problems in $\beta$-Ti alloys were concluded to result from decohesion [4-6].

Microstructural modification and mechanical properties improvement of $\alpha$ - and $(\alpha+\beta)$-Ti alloys through thermohydrogen processing have been extensively studied by many investigators [7-12]. Ti-153, as a typical $\beta$-Ti alloy, was chosen in this study for investigating the variations in microstructure and mechanical properties after cyclic electrolytic hydrogenation and subsequent solution treatment.

\section{Experiments}

The specimens were grouped into three sets according to the preheating conditions (1) A0, machined from the as-received sheet; (2) B0, subjected A0 specimens to vacuum annealing at $1.33 \times 10^{-4} \mathrm{~Pa}$ from room temperature to $1000^{\circ} \mathrm{C}$, then held for $0.5 \mathrm{hr}$, and finally furnace cooled to room temperature; (3) $\mathrm{C} 0$, heated $\mathrm{A} 0$ specimens in a muffle furnace at $500^{\circ} \mathrm{C}$ for $0.5 \mathrm{hr}$ and finally air cooled to room temperature. Chemical composition of the as-received sheet was listed in Table 1 . The specimens were sheared to be $40 \times 14 \times 4 \mathrm{~mm}^{3}$, abraded with emery paper (up to grit 1200), and then lapped with alumina powder to minimize the interference of surface oxides on hydrogenation. The surface roughness was measured by employing surface roughness tester (MITUTOYO SV402) and listed in Table 2.

Electrolytic hydrogenation was performed at $50 \mathrm{~mA} / \mathrm{cm}^{2}$ for $1 \mathrm{hr}$ and $5 \mathrm{~mA} / \mathrm{cm}^{2}$ for $10 \mathrm{hrs}$ in $1 \mathrm{~N} \mathrm{H}_{2} \mathrm{SO}_{4(\mathrm{aq})}$ by adding $0.1 \mathrm{~g} / \mathrm{L} \mathrm{As}_{2} \mathrm{O}_{3}$, respectively. The subsequent solution treatments were operated in a muffle furnace at $300^{\circ} \mathrm{C}$ for $2 \mathrm{hrs}$. Processes were grouped and denoted by $I j K l$ according to the treating conditions (cathodic charging, heat treatment, and cycle time), where $I$ and $K$ correspond to the treatments ( $I$ or $K=\mathrm{H}$ means the specimen charged at $50 \mathrm{~mA} / \mathrm{cm}^{2}$ for $1 \mathrm{hr} ; I$ or $K=\mathrm{L}$ means the specimen charged at $5 \mathrm{~mA} / \mathrm{cm}^{2}$ for $10 \mathrm{hrs} ; I$ or $K=$ T means the specimen heat treated in a muffle furnace at $300^{\circ} \mathrm{C}$ for $2 \mathrm{hrs}$, respectively, while $j$ or $l=1$ means the first cycle, $j$ or $l=2$ means the second cycle, 
TABLE 1: Analyzed composition of the as-received Ti-153 sheets (wt.\%).

\begin{tabular}{lccccccccc}
\hline $\mathrm{H}$ & $\mathrm{C}$ & $\mathrm{N}$ & $\mathrm{O}$ & $\mathrm{Fe}$ & $\mathrm{Al}$ & $\mathrm{Cr}$ & $\mathrm{Sn}$ & $\mathrm{V}$ & $\mathrm{Ti}$ \\
\hline 0.015 & 0.05 & 0.05 & 0.13 & 0.25 & $2.5 \sim 3.5$ & $2.5 \sim 3.5$ & $2.5 \sim 3.5$ & $14.0 \sim 16.0$ & balanced \\
\hline
\end{tabular}

TABLE 2: The surface roughness of Ti-153 sheet specimens after various processing.

\begin{tabular}{lccc}
\hline Processing & $R_{a}(\mu \mathrm{m})$ & $R_{q}(\mu \mathrm{m})$ & $R_{t}(\mu \mathrm{m})$ \\
\hline A0 & 0.073 & 0.090 & 0.61 \\
B0 & 0.095 & 0.121 & 0.83 \\
C0 & 0.084 & 0.104 & 0.76 \\
\hline
\end{tabular}

$R_{a}$ : The arithmetic mean of the departure of the profile from the mean line.

$R_{q}$ : The root-mean-square parameter corresponding to $R_{a}$.

$R_{t}$ : The maximum peak to valley height of the profile in the assessments.

$j$ or $l=3$ means the third cycle, ..., etc.). For instance, H2T2 means that the specimen was hydrogenated in the first cycle at $50 \mathrm{~mA} / \mathrm{cm}^{2}$ for $1 \mathrm{hr}$, followed by a heat treatment at $300^{\circ} \mathrm{C}$ for $2 \mathrm{hrs}$, and then proceeded the same treatments in the second cycle. All the process designations and processing parameters were gathered in Table 3. The whole experimental procedure was schematically shown in Figure 1.

The effects of processing parameters on the microstructural changes and the electrolytic hydrogenation efficiency were evaluated qualitatively and quantitatively by utilizing X-ray diffractometry (XRD: X'Pert PRO MPD, PANalytical, Netherlands, $45 \mathrm{kV}-40 \mathrm{~mA}$ ), metallographic optical microscopy (MOM), glow discharge optical spectrometry (GDOS; LECO GDS-750), and elemental analysis (EA: elementar VarioEL-III), respectively. The hardness variation at the near surface was measured by utilizing Akashi Vickers hardness tester (MVK-H100).

\section{Results and Discussion}

3.1. Structural Variations. The microphotographs of surface and cross-sectional views of the as-received and processed sheets were shown in Figures 2, 3, and 4, respectively. Figure 2(a) showed that the grain size of A0 specimens on the rolling surface is $30 \mu \mathrm{m}$. Figure 2(b) was the microstructure of long transverse side of A0 sheets. The rolled sheets did not show an exceedingly elongated grain structure. The microstructures in Figures 3(a) and 3(b) were relatively equiaxed. Having been subjected to vacuum annealing at $1000^{\circ} \mathrm{C}$ for $0.5 \mathrm{hr}$, the original small grains of A0 specimens grew to more than $300 \mu \mathrm{m}$ in B0 specimens (Figures 3(a) and $3(\mathrm{~b})$ ). Heat treating A0 specimens at $500^{\circ} \mathrm{C}$ for $0.5 \mathrm{hr}$ and air cooling to room temperature did not effectively alter the microstructure of A0 specimens. The microstructure of C0 specimens (Figures 4(a) and 4(b)) was similar to those of A0 ones.

The XRD patterns of $\mathrm{A} 0, \mathrm{~B} 0$, and $\mathrm{C} 0$ specimens were shown in Figure 5. Annealing at $\beta$ phase region for B0 treatment led to obvious variation in preferred orientation (from $\beta(110)$ to $\beta(200)$ ) while no $\alpha$ precipitation and $\beta$ peak shift were found. C0 treatment, however, annealing

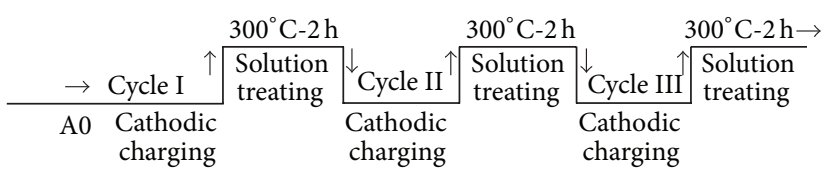

(a)

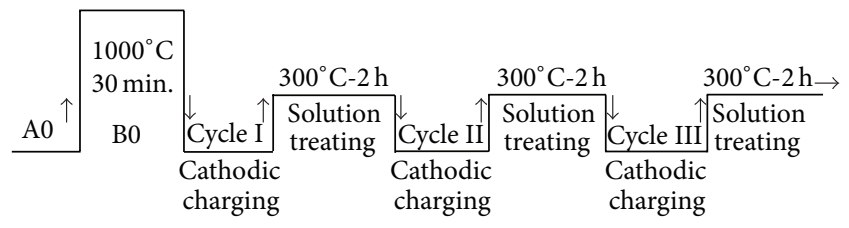

(b)

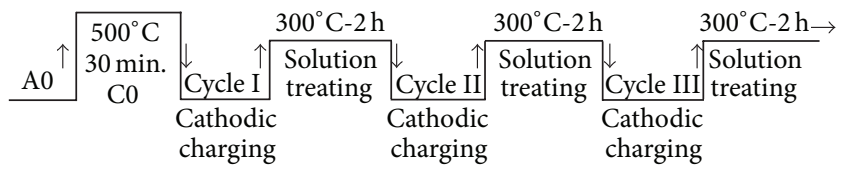

(c)

FIGURE 1: Schematic diagrams of the designed cyclic hydrogenationsolid solution treatment for (a) A0, (b) B0, and (c) C0 sheets.

at $\alpha$ phase region resulted in slight $\alpha$ phase formation and $\beta$ peaks shift without appreciable texture change [13]. Subsequent microstructural changes of $\mathrm{A} 0, \mathrm{~B} 0$, and $\mathrm{C} 0$ specimens due to thermal annealing, hydrogen absorption, hydrogen evolution, and redistribution in the $\beta$-Ti substrate during cyclic hydrogenation and solution heat treatment were shown in Figures 6, 7, 8, and 9, respectively. The XRD patterns in Figures 6(a), 6(b), and 6(c) for T1, T2, T3, and T4 processes performed on $\mathrm{A} 0, \mathrm{~B} 0$, and $\mathrm{C} 0$ sheets did not show significant phase transformation or texture change in comparison with those corresponding patterns of $\mathrm{A} 0, \mathrm{~B} 0$, and $\mathrm{C} 0$ ones. The accumulated heating period up to 8 hours at $300^{\circ} \mathrm{C}$ did not bring about detectable $\alpha$ signal in the XRD patterns of AT4 and BT4 specimens. The C0 specimen, however, treated at $500^{\circ} \mathrm{C}$ for only 0.5 hour can lead to observable $\alpha$ peaks in Figure 5. Independent employment of solution heat treatment has minute effect on the microstructural changes of $\mathrm{Ti}-153$ under the designed testing conditions while the subjection of cyclic hydrogenation combining postsolution heat treating to $\mathrm{A} 0, \mathrm{~B} 0$, and $\mathrm{C} 0$ specimens resulted in appreciable microstructural evolutions.

The diffraction peaks of $\beta$ phase presented in the XRD patterns of $\mathrm{A} 0$ and $\mathrm{C} 0$ sheets were gradually depressed and shifted to left while not significantly broadened after every hydrogenation process and would back shift to right slightly after the successive solution heating process. The variations of $\beta$ diffraction peaks of B0 specimens, however, did not show the same tendency as that of A0 and C0 ones. The $\alpha$ peaks in C0 patterns diminished eventually 
TABLE 3: Process designations and the associated processing parameters.

Process designations
$\mathrm{T} 1$
$\mathrm{Tn} 1$
$\mathrm{H} 1 \mathrm{~T} 1$
$\mathrm{~T} 1 \mathrm{H} 2$
$\mathrm{HnTn}$
$\mathrm{T} 1 \mathrm{~T} 1$
$\mathrm{~T} 1 \mathrm{~L} 2$
$\mathrm{TnLn}+1$

(a)
The associated processing parameters

Heating for $2 \mathrm{hrs}$ at $300^{\circ} \mathrm{C}$ and then air cooling to room temperature Specimens heated for $n$ times followed the T1 conditions $(n \geqq 2)$ Hydrogenated at $50 \mathrm{~mA} / \mathrm{cm}^{2}$ for $1 \mathrm{hr}$ in $1 \mathrm{~N} \mathrm{H}_{2} \mathrm{SO}_{4(\mathrm{aq})}+0.1 \mathrm{~g} / \mathrm{L} \mathrm{As}_{2} \mathrm{O}_{3}$ Hydrogenated at $5 \mathrm{~mA} / \mathrm{cm}^{2}$ for $10 \mathrm{hrs}$ in $1 \mathrm{~N} \mathrm{H}_{2} \mathrm{SO}_{4(\mathrm{aq})}+0.1 \mathrm{~g} / \mathrm{L} \mathrm{As}_{2} \mathrm{O}_{3}$ $\mathrm{H} 1$ treated specimens followed by a further $\mathrm{T} 1$ treatment H1T1 treated specimens followed by a further $\mathrm{H} 1$ treatment Tn-1Hn treated specimens followed by a further T1 treatment $(n \geqq 2)$ HnTn treated specimens followed by a further H1 treatment $(n \geqq 2)$ L1 treated specimens followed by a further T1 treatment L1T1 treated specimens followed by a further L1 treatment Tn-1Ln treated specimens followed by a further T1 treatment $(n \geqq 2)$ LnTn treated specimens followed by a further L1 treatment $(n \geqq 2)$

FIGURE 2: Metallographic microphotographs on (a) rolling surface and (b) long transverse side of A0 sheets.

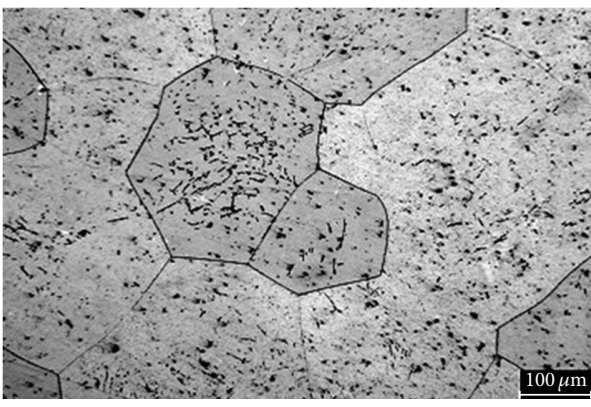

(a)

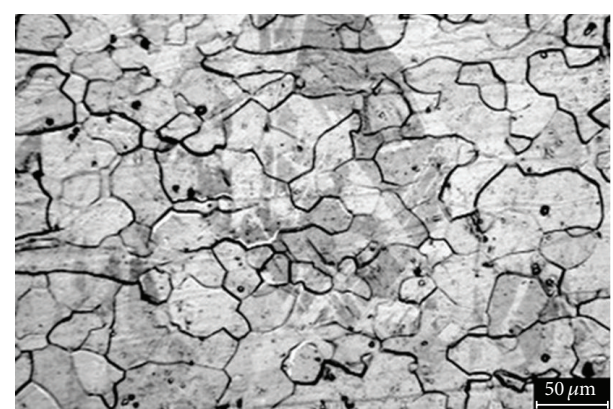

(b)

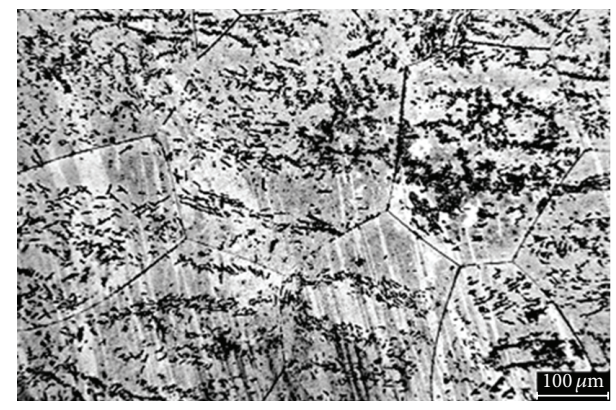

(b)

FIGURE 3: Metallographic microphotographs on (a) rolling surface and (b) long transverse side of B0 sheets.

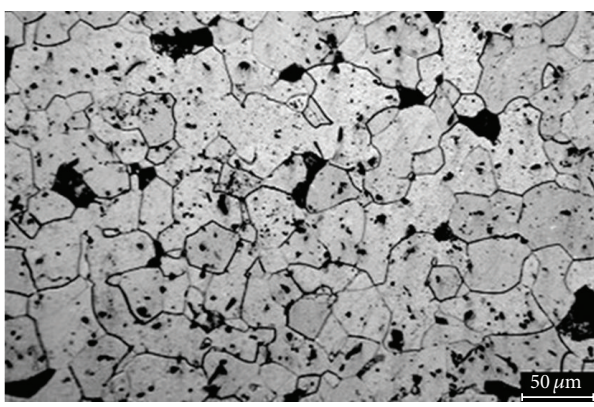

(a)

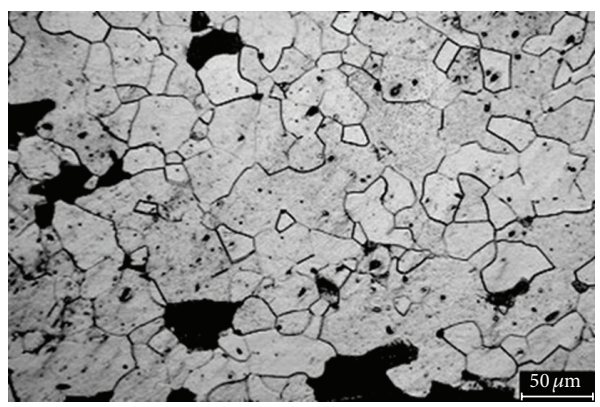

(b)

FIGURE 4: Metallographic microphotographs on (a) rolling surface and (b) long transverse side of C0 sheets. 


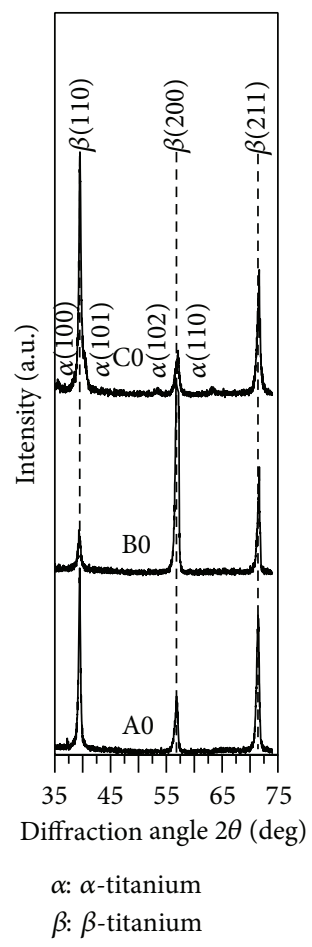

FIGURE 5: The respective XRD pattern for $\mathrm{A} 0, \mathrm{~B} 0$, and $\mathrm{C} 0$ sheets.

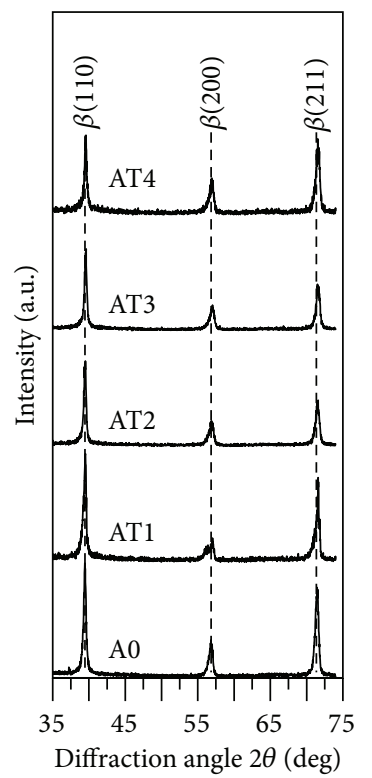

$\beta: \beta$-titanium

(a)

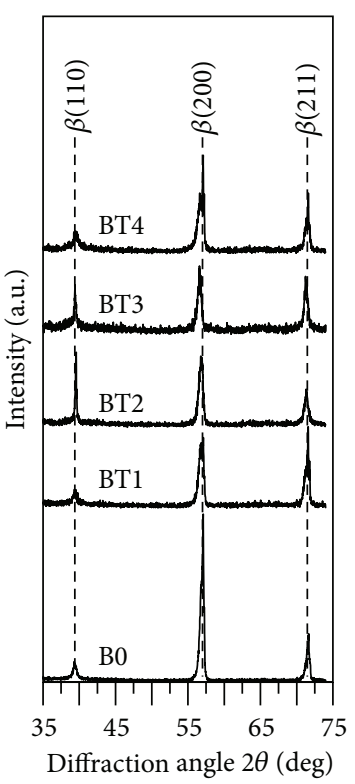

$\beta: \beta$-titanium

(b)

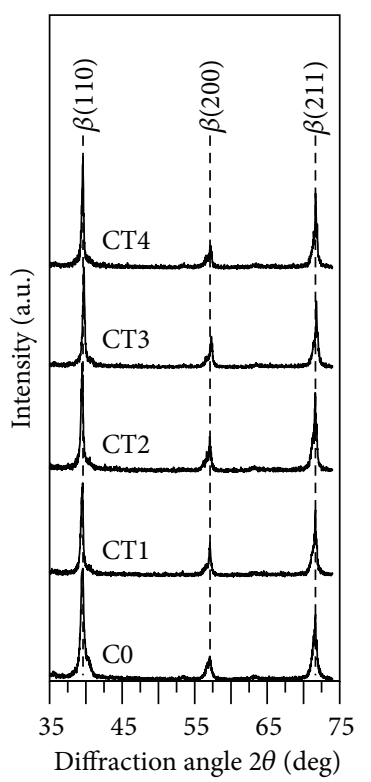

$\beta: \beta$-titanium

(c)

FIGURE 6: XRD patterns for specimens after cyclic annealing (a) ATl, (b) BTl, and (c) CTl series.

after $\mathrm{CH} 4 \mathrm{~T} 4$ and CT2L3 treatments. The most pronounced angular discrepancy found in the XRD patterns of various series of specimens was to be of AT3L4, BT3L4, and CT3L4 ones (Figures 6 to 9). The differences of angular position $(2 \theta)$ of $\beta(211)$ for AT3H4, BT3H4, and CT3H4 (in contrast to A0, $\mathrm{B} 0$ and $\mathrm{C} 0$ resp.) were $0.38^{\circ}, 0.68^{\circ}$, and $0.78^{\circ}$, while those for AT3L4, BT3L4, and CT3L4 were $1.64^{\circ}, 2.00^{\circ}$, and $2.48^{\circ}$, respectively. Since lower charging current densities would lead to higher hydrogenation efficiency [14-16], the discussion about the effects of hydrogen uptake on the angular shift and phase transformation was hereafter confined to the ATjLk, BTjLk,and CTjLk series. 


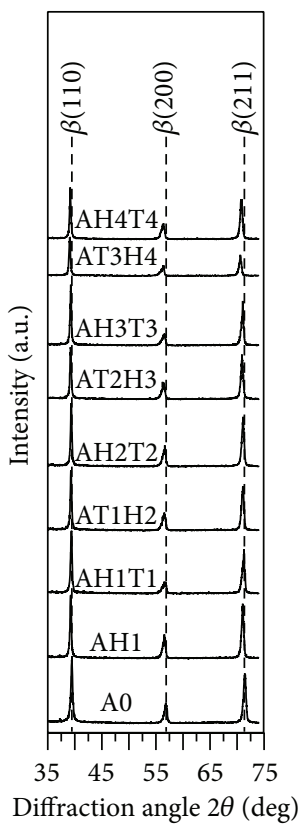

$\beta: \beta$-titanium

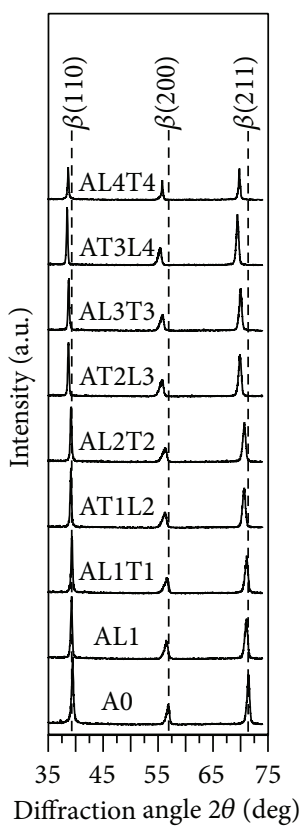

$\beta: \beta$-titanium (a)

(b)

FIGURE 7: XRD patterns for specimens after successive (a) $\mathrm{AH} \mathrm{T} l$ and (b) ALjTl treatments.

The magnitude of angular shift and the FWHM of peaks $\beta(110), \beta(200)$ and $\beta(211)$ for $\mathrm{A} 0, \mathrm{~B} 0, \mathrm{C} 0, \mathrm{AT} 3, \mathrm{BT} 3, \mathrm{CT} 3$, AT3L4, BT3L4 and CT3L4 specimens were listed in Table 4. $\mathrm{T} 3$ process was a blank test in contrast to the corresponding T3L4 process. According to the data grouped in Table 4, the crystallinity of cyclically hydrogenated specimens were superior to that of original and cyclic heat treated ones. T3 treatment was basically a cyclic precipitation process of $\alpha$ phase operated at $300^{\circ} \mathrm{C}$. The absorbed hydrogen atoms occupying the interstitial sites during cathodic charging expanded the lattice, while the dissolved aluminum precipitated from the $\beta$ matrix during heating relaxed the lattice expansion. The magnitude of angular shift of peaks $\beta(110), \beta(200)$ and $\beta(211)$ for AT3, BT3 and CT3 specimens are positive due to lattice relaxation in contrast to those correspondingly negative values for AT3L4, BT3L4 and CT3L4 ones due to lattice expansion.

3.2. Compositional Analyses. Figure 10 shows the depth profiles of hydrogen distribution at the near surface of AT3L4, BT3L4 and CT3L4 specimens. After the A0 sheets had been vacuum annealed at $1000^{\circ} \mathrm{C}$ for half an hour and followed by a furnace cooling to room temperature, the defects density of B0 sheets were significantly reduced and all the solute atoms were dissolved into the matrix. There were limited defective regions for ingressive hydrogen so that the hydrogen depth profile for BT3L4 in Figure 10 located appreciably lower than those for AT3L4 and CT3L4. An annealing treatment at $500^{\circ} \mathrm{C}$ for half an hour and a following air cooling performed on $\mathrm{A} 0$ sheets also reduced defects density of $\mathrm{C} 0$ sheets

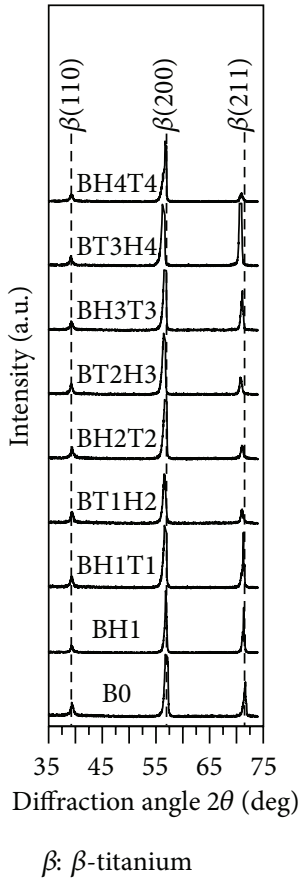

(a)

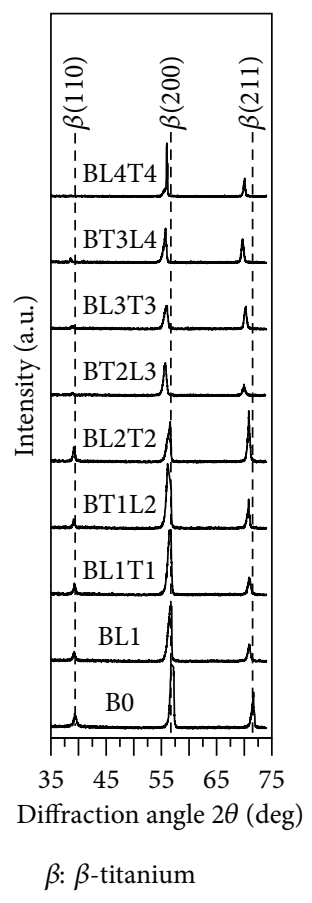

(b)
FIGURE 8: XRD patterns for specimens after successive (a) $\mathrm{BH} j \mathrm{~T} l$ and (b) $\mathrm{BLj} \mathrm{T} l$ treatments.

but promoted aluminum to come out of the $\beta$ matrix to form appreciable $\alpha$ phase (Figure 5). The larger amount of aluminum precipitation during heating, the higher extent of the lattice strain relaxed, thus, resulted in residential space to accommodate much more interstitial hydrogen.

Positive difference between hydrogen absorption and evolution eventually caused structural changes. Hydrogen diffused into $\beta$ structure induced dilatation of matrix and resulted in the enlargement of respective d-spacing, thus, decreased the diffraction angle $2 \theta$ of corresponding $\beta$ peaks. Since C0 sheets with lower defects density but far more relaxed interstitial sites than those of $\mathrm{A} 0$ ones, the hydrogen uptake for CT3L4 just slightly inferior to that for AT3L4 while with lower volume expansion (C0 versus A0: $-0.372 \%$ ). The variations in lattice constant and volume expansion for typical treatments were analyzed by using Nelson-Riley approach [17] and listed in Table 5. After A0 sheets had been $\mathrm{B} 0$ and $\mathrm{C} 0$ treated, the volume contraction rate for $\mathrm{B} 0$ and C0 ones were $0.186 \%$ and $0.372 \%$, respectively. T3 treatment led to further stress relaxation of $\mathrm{A} 0, \mathrm{~B} 0$ and $\mathrm{C} 0$ sheets of which the volume contraction rate was all $0.031 \%$, while T3L4 treatment resulted in evident volume expansion rate of $\mathrm{A} 0$ (3.90\%), B0 (2.04\%) and C0 (5.40\%) ones, respectively.

The appreciable angular shifts in diffracted $\beta$ peaks for AT3L4, BT3L4 and CT3L4 leading to smaller FWHM means that the hydrogenated layer at the near surface of AT3L4, BT3L4 and CT3L4 specimens have long range order. This, in turn, implies that an almost homogeneously hydrogenated near surface was the prerequisite. It can be seen from Figure 10 that the linear section of the depth profiles are with 
TABLE 4: The magnitude of angular shift and (/) the FWHM in degree of peaks $\beta(110), \beta(200)$, and $\beta(211)$ for some treated specimens corresponding to $\mathrm{A} 0, \mathrm{~B} 0$, and $\mathrm{C} 0$ ones, respectively.

\begin{tabular}{lccc}
\hline Specimen & $\beta(110)$ & $\beta(200)$ & $\beta(211)$ \\
\hline A0 & $39.47(-/ 0.19)$ & $56.83(-/ 0.30)$ & $71.43(-/ 0.23)$ \\
AT3 & $39.61(0.14 / 0.20)$ & $57.03(0.20 / 0.32)$ & $71.75(0.32 / 0.32)$ \\
AT3L4 & $38.69(-0.78 / 0.14)$ & $55.73(-1.10 / 0.30)$ & $69.79(-1.64 / 0.24)$ \\
B0 & $39.31(-/ 0.29)$ & $57.09(-/ 0.23)$ & $71.67(-/ 0.21)$ \\
BT3 & $39.41(0.10 / 0.16)$ & $57.21(0.12 / 0.27)$ & $71.81(0.14 / 0.29)$ \\
BT3L4 & $38.55(-0.76 / 0.12)$ & $55.77(-1.32 / 0.23)$ & $69.67(-2.00 / 0.23)$ \\
C0 & $39.49(-/ 0.22)$ & $57.11(-/ 0.34)$ & $71.65(-/ 0.25)$ \\
CT3 & $39.60(0.11 / 0.14)$ & $57.21(0.10 / 0.20)$ & $71.77(0.12 / 0.19)$ \\
CT3L4 & $38.29(-1.20 / 0.11)$ & $55.39(-1.82 / 0.14)$ & $69.17(-2.48 / 0.16)$ \\
\hline
\end{tabular}

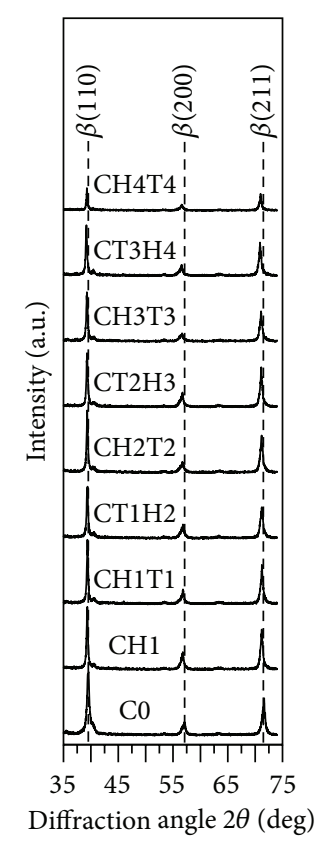

$\beta$ : $\beta$-titanium

(a)

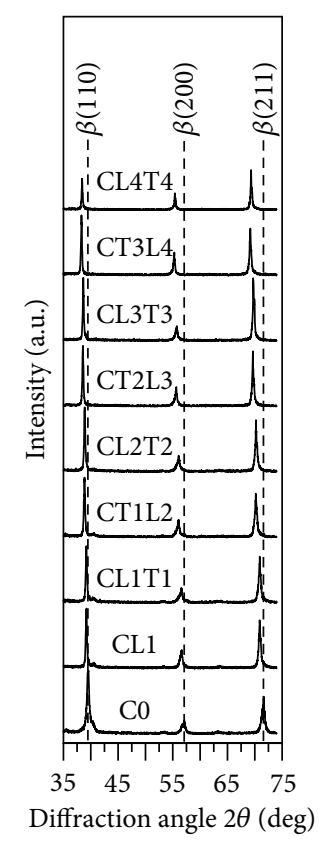

$\beta$ : $\beta$-titanium

(b)

FIgURE 9: XRD patterns for specimens after successive (a) $\mathrm{CH} \mathrm{Tl} l$ and (b) CLjTl treatments.

slight gradient inclined from the surface into the interior for the AT3L4, BT3L4 and CT3L4 treatments. The steeply and mildly declined hydrogen depth profiles of CP-Ti and Ti-6Al$4 \mathrm{~V}$ alloy processed with the similar parameters as applied to AT3L4 and AT3H4 specimens, respectively. The results had been published before $[11,18]$ and were partly extracted here for comparison. In [11], the appreciable concentration gradient for $\mathrm{Ti}-6 \mathrm{Al}-4 \mathrm{~V}$ alloy at the near surface led to the broadened $\alpha$ and $\beta$ diffraction peaks of Ti-6Al- $4 \mathrm{~V}$ specimens with $\mathrm{A} 3 \mathrm{H} 4$ processing.

The electrolytic hydrogenating parameters performed on the CP-Ti and Ti-6Al-4V specimens were $5 \mathrm{~mA} / \mathrm{cm}^{2}$ for $30 \mathrm{hrs}$ and $50 \mathrm{~mA} / \mathrm{cm}^{2}$ for $3 \mathrm{hrs}$ in $1 \mathrm{~N} \mathrm{H}_{2} \mathrm{SO}_{4(\mathrm{aq})}+0.1 \mathrm{~g} / \mathrm{L}$ $\mathrm{As}_{2} \mathrm{O}_{3}$, respectively. The total Faraday numbers for the two

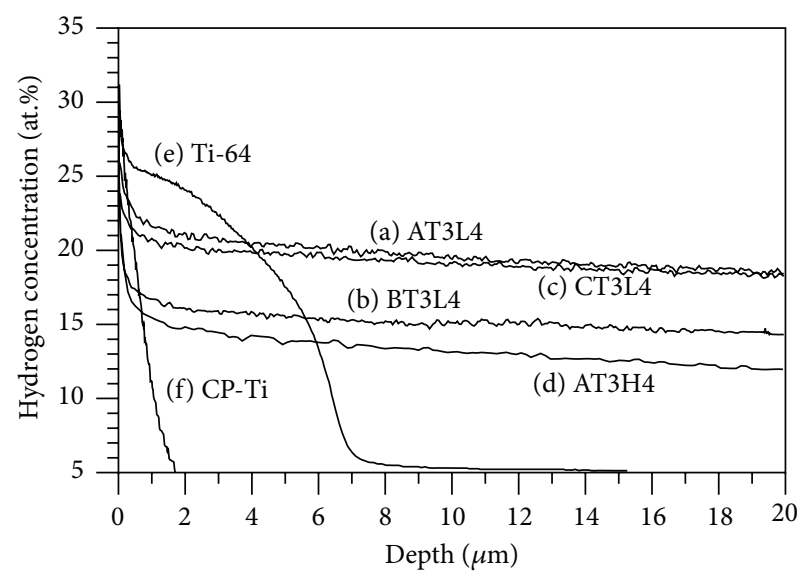

FIgURE 10: Hydrogen distribution depth profiles at the near surface after (a) AT3L4, (b) BT3L4, (c) CT3L4, and (d) AT3H4 treatments. The depth profiles for the treatments similar to AT3H4 and AT3L4 performed on (e) Ti-64 and (f) CP-Ti respectively were also attached for comparison.

processes were three times as large as those applied to AT3L4 and AT3H4 ones. Comparison of the depth profiles between AT3L4 and AT3H4 ones quantitatively manifests that lower applied current density leading to higher charging efficiency. Compare the depth profiles of CP-Ti with AT3L4 and Ti-6Al$4 \mathrm{~V}$ with AT3H4 to see the different hydrogenating behavior among $\alpha, \alpha+\beta$, and $\beta$ titanium alloys. Obviously bcc structure of $\beta$ phase offers a more open route and broader space for the diffusion and accommodation of hydrogen in titanium.

3.3. Hardness Measurements. There are various hydrogen accommodating microstructures such as interstitial sites, vacant sites, dislocation core, grain boundaries, and voids in the specimens. Shifts of diffraction peaks can arise from the occupation of interstitial sites only; besides, higher content of hydrogen absorption would result in higher dislocation density in the matrix [19]. This is the reason why shifts of $\beta$ diffraction peaks cannot be served as a quantitative measurement of hydrogen absorption, even qualitative, of the processed specimens but can be directly related to lattice 
TABLE 5: Variations in lattice constant and volume expansion rate between typical treatments.

\begin{tabular}{lccc}
\hline Treatment & & Variation & Lolume expansion \\
\hline A0 & Lattice constant $(\AA)$ & - & - \\
AT3 (versus A0) & 3.234 & $-0.031 \%$ & $-0.093 \%$ \\
AT3L4 (versus A0) & 3.233 & $1.30 \%$ & $3.90 \%$ \\
B0 (versus A0) & 3.275 & $-0.062 \%$ & $-0.186 \%$ \\
BT3 (versus B0) & 3.232 & $-0.031 \%$ & $-0.093 \%$ \\
BT3L4 (versus B0) & 3.231 & $0.68 \%$ & $2.04 \%$ \\
C0 (versus A0) & 3.253 & $-0.124 \%$ & $-0.372 \%$ \\
CT3 (versus C0) & 3.230 & $-0.031 \%$ & $-0.093 \%$ \\
CT3L4 (versus C0) & 3.229 & $1.80 \%$ & $5.40 \%$ \\
\hline
\end{tabular}

TABLE 6: $H_{S}, H_{N}$, and $H_{B}$ for typical specimens (Vickers hardness measured at the load of $50 \mathrm{gw}$ ).

\begin{tabular}{|c|c|c|c|c|c|c|c|c|c|c|c|}
\hline \multirow{2}{*}{$\begin{array}{l}\text { Process } \\
\text { designation }\end{array}$} & \multirow{2}{*}{$H_{S}$} & \multicolumn{9}{|c|}{$H_{N}(\mu \mathrm{m})$} & \multirow{2}{*}{$\begin{array}{c}H_{C} \\
H_{N}(500)\end{array}$} \\
\hline & & 50 & 100 & 150 & 200 & 250 & 300 & 350 & 400 & 450 & \\
\hline A0 & 236.9 & & 241.2 & & 226.3 & & 230.4 & & 231.7 & & 234.6 \\
\hline AT3 & 264.5 & & & & & & & & & & \\
\hline AT3L4 & 409.3 & 376.2 & 387.6 & 378.6 & 371.4 & 380.0 & 356.6 & 346.5 & 336.9 & 345.6 & 346.1 \\
\hline AT4 & 301.1 & & 257.2 & & 260.5 & & 250.3 & & 254.2 & & 253.1 \\
\hline B0 & 179.5 & & 185.3 & & 177.2 & & 164.7 & & 174.3 & & 169.8 \\
\hline BT3 & 277.9 & & & & & & & & & & \\
\hline BT3L4 & 344.7 & 364.1 & 364.7 & 364.0 & 357.0 & 355.6 & 347.3 & 338.7 & 330.4 & 336.9 & 331.2 \\
\hline BT4 & 288.2 & & 219.6 & & 221.2 & & 217.7 & & 213.8 & & 219.8 \\
\hline $\mathrm{CO}$ & 314.7 & & 318.6 & & 317.4 & & 310.6 & & 317.9 & & 318.2 \\
\hline CT3 & 330.7 & & & & & & & & & & \\
\hline CT3L4 & 491.1 & 476.3 & 467.2 & 436.8 & 443.1 & 438.7 & 436.5 & 429.8 & 432.7 & 427.3 & 423.8 \\
\hline CT4 & 348.1 & & 327.9 & & 322.6 & & 317.4 & & 338.1 & & 326.7 \\
\hline
\end{tabular}

expansion and, thus, the hardness elevation. Zhao et al. [19] found that hydrogen atoms absorbed by titanium alloys would preferentially inhabit vacant sites and then dislocations rather the interstitial sites in the initial stage, which offers no solid-solution strengthening effect on the microstructure [20].

A0 sheets had been rolled and process annealed to accumulate $50 \%$ in thickness reduction. Large amount of point and line defects were stored in A0 sheets during the processing. $\mathrm{C} 0$ sheets were obtained by subjecting A0 ones to an annealing treatment at $500^{\circ} \mathrm{C}$ for $30 \mathrm{~min}$., which lowered the densities of point (vacancies and substitutional solute atoms) and line (dislocations) defects in the $\mathrm{C} 0$ sheets. Under the same charging condition, the amount of interstitial sites occupied by the ingressive hydrogen in the processed specimens determined the lattice dilatation, thus, angular shift of diffracted $\beta$ peaks, and finally the hardening effect on the specimens. In comparison with A0 specimens, $\mathrm{C} 0$ ones processed in the $\alpha$-phase region $\left(500^{\circ} \mathrm{C}\right)$ experienced precipitation hardening to compete against annealing softening. The softening arose from two sources (1) recovery of A0 specimens annealed at $500^{\circ} \mathrm{C}$ for half an hour and (2) the major $\alpha$ element in Ti-15333 alloy, aluminum, precipitated out of $\beta$ matrix eliminated the effect of solid-solution strengthening. The angular shift and changes in preferred orientation of $\beta$ phase (Table 4 and Figure 5) in contrast to that for A0 treatment are however not significant. Aluminum atoms diffusing away from $\beta$ matrix also led to the lattice resuscitation (Table 5 ). In comparison with $\mathrm{B} 0$ specimens, precipitation of aluminum relaxed the lattice strain and elevated the accommodating capacity of hydrogen for C0 specimens during successive cathodic charging processes. Hardness elevation (491.1) and lattice dilatation (1.80\%) of CT3L4 specimens were obviously higher than those of AT3L4 (409.3 and 1.30\%) and BT3L4 ones (344.7 and 0.68\%).

Table 6 showed Vickers hardness numbers (VHN) measured at different areas on the typical specimens, where $H_{S}$, $H_{N}$, and $H_{C}$ were VHN obtained at surface and near surface at various depths, respectively. The core hardness $H_{C}$ is the $H_{N}$ measured at the depth of $500 \mu \mathrm{m}$. The correspondingly lowest hardness for specimens of series B arose from lower dislocation density, larger grain size $(300 \mu \mathrm{m})$, and higher average aluminum content in the matrix (no precipitation hardening) of B0 sheets, while the correspondingly highest hardness for specimens of series $\mathrm{C}$ was from the controlled grain size $(30 \mu \mathrm{m})$ and precipitation hardening.

The hardening efficiencies (HE) for typical specimens were listed in Table 7. Obviously, the differences of VHN 


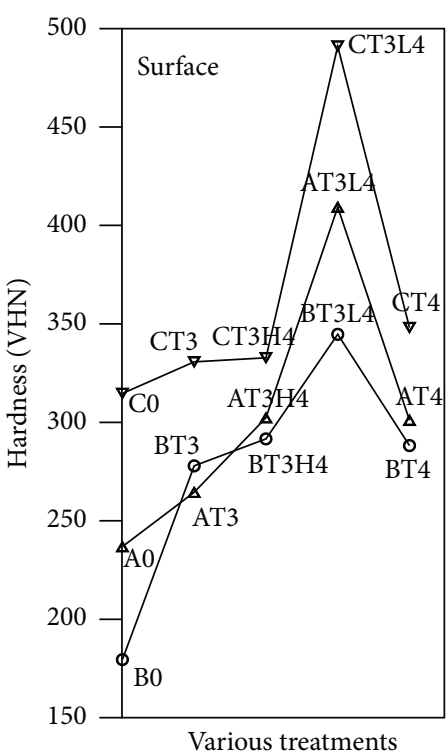

(a)

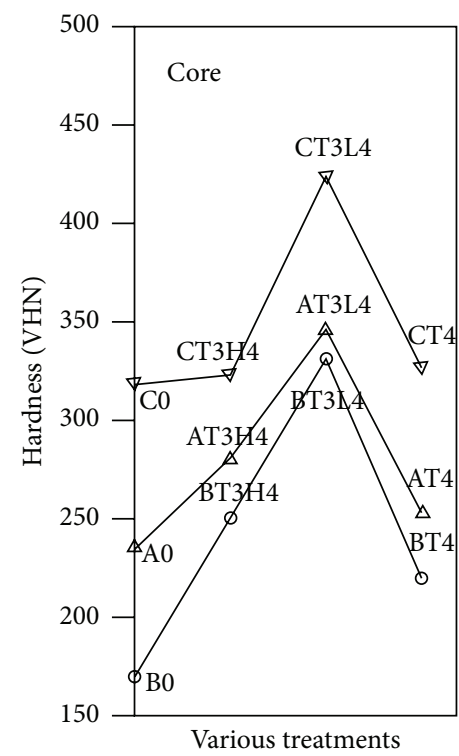

(b)

FIgURE 11: Variations of VHN for different treatments at (a) surface and (b) core.

TABLE 7: Hardening efficiency for typical specimens.

\begin{tabular}{lcc}
\hline Process designation & $H_{S} / \mathrm{HE}$ & $H_{\mathrm{C}} / \mathrm{HE}$ \\
\hline A0 & 236.9 & 234.6 \\
AT3 & $264.5 / 11.7 \%$ & - \\
AT3L4 & $409.3 / 72.8 \%$ & $346.1 / 47.5 \%$ \\
AT4 & $301.1 / 27.1 \%$ & $253.1 / 7.9 \%$ \\
B0 & 179.5 & 169.8 \\
BT3 & $277.9 / 54.8 \%$ & - \\
BT3L4 & $344.7 / 92.0 \%$ & $331.2 / 95.1 \%$ \\
BT4 & $288.2 / 60.6 \%$ & $219.8 / 29.4 \%$ \\
C0 & 314.7 & 318.2 \\
CT3 & $330.7 / 5.1 \%$ & - \\
CT3L4 & $491.1 / 56.1 \%$ & $423.8 / 33.2 \%$ \\
CT4 & $348.1 / 10.6 \%$ & $326.7 / 2.7 \%$ \\
\hline
\end{tabular}

between T0 and T3 specimens were derived from precipitation hardening, while those between T3 and T3L4 ones were derived from hydrogenation. The HE for CT3 and CT4 were the specimens correspondingly lowest ones among T3 and $\mathrm{T} 4$ because precipitating hardenability of $\mathrm{C} 0$ specimen was exhausted during $500^{\circ} \mathrm{C}$ pretreatment. $H_{S}$ of A0 sheets increased from 236.9 to 264.5 (AT3), and then 302.3 (AT3H4) and 409.3 (AT3L4) finally dropped to 301.1 (AT4). The surface and core hardness variations for specimens of $\mathrm{A}, \mathrm{B}$, and $\mathrm{C}$ series were shown in Figure 11. It is reasonable to see that surface hardness is correspondingly higher than core hardness. The hardness variations of surface and core for A, $\mathrm{B}$, and $\mathrm{C}$ series, however, follow the similar tendency. T3L4 is the optimal process for surface and core hardening for A, B, and $\mathrm{C}$ sheets. The maximum hardness elevation efficiencies of $H_{S}$ and $H_{C}$ for series A are $72.8 \%\left(H_{S}\right)$ and $47.5 \%\left(H_{C}\right)$. Those for $\mathrm{B}$ and $\mathrm{C}$ series are $92.0 \%\left(H_{S}\right), 95.1 \%\left(H_{C}\right)$ and $56.1 \%\left(H_{S}\right)$,
$33.2 \%\left(H_{C}\right)$, respectively. Since the precipitating hardenability of specimens was gradually consumed while the hydrogen uptake of them increased with numbers of cyclic electrolytic hydrogenation, the hardening effect deriving from solidsolution strengthening of hydrogen eventually overrode that from precipitation hardening.

\section{Conclusions}

(i) No precipitates of $\alpha$ phase were observed for Ti-153 alloy after vacuum annealed in the $\beta$-phase region (at $1000^{\circ} \mathrm{C}$ ) by employing MOM and XRD but $\beta$ grains grew significantly from $30 \mu \mathrm{m}$ (A0) to $300 \mu \mathrm{m}$ (B0) associated with evident annealing texture and softening. Aging at $\alpha$-phase region $\left(\right.$ at $500^{\circ} \mathrm{C}$ ) for 30 min led to almost no grain growth and texture change but appreciable hardness enhancement for $\mathrm{C} 0$ specimens.

(ii) Application of cyclic heat treating at $300^{\circ} \mathrm{C}$ (lower $\alpha$ phase region) to $\mathrm{A} 0, \mathrm{~B} 0$, and $\mathrm{C} 0$ specimens had nearly no influence on XRD patterns, while applying cyclic hydrogenation-solution treatment to those specimens led to significant hydrogen absorption and lattice dilatation. Hydrogen absorption from processing helped to increase the crystallinity of the specimens. The ascending order of hydrogen uptake was BT3L4, CT3L4, and AT3L4, while the volume expansion rates for AT3L4, BT3L4, and CT3L4 corresponding to A0, B0, and C0 ones were $3.90 \%, 2.04 \%$, and $5.40 \%$, respectively.

(iii) $\mathrm{A} 0, \mathrm{~B} 0$, and $\mathrm{C} 0$ sheets used in this study can be precipitation hardened by cyclic heat treating, however, with lower hardening efficiencies compared to those processed by employing cyclic hydrogenation-solution 
treatment. The process for the maximum $\mathrm{HE}$ of $H_{S}$ and $H_{C}$ was BT3L4, while that for the maximum hardness was CT3L4. Since the precipitating hardenability of specimens was gradually consumed, the hardening effect deriving from solid-solution strengthening of hydrogen eventually overrode that from precipitation hardening. Process T3L4 is suitable for surface and core hardening for $\mathrm{A}, \mathrm{B}$, and $\mathrm{C}$ sheets.

\section{Conflict of Interests}

The authors declare that there is no conflict of interests regarding the publication of this paper.

\section{References}

[1] W. F. Smith, Structure and Properties of Engineering Alloys, McGraw-Hill, New York, NY, USA, 1st edition, 1981.

[2] I. J. Polmear, Light Alloys, Edward Arnold, London, UK, 1st edition, 1981.

[3] E. W. Collings, The Physical Metallurgy of Titanium Alloys, ASM International, Metals Park, Ohio, USA, 1st edition, 1984.

[4] M. L. Wasz, F. R. Brotzen, R. B. McLellan, and A. J. Griffin Jr., "Effect of oxygen and hydrogen on mechanical properties of commercial purity titanium," International Materials Reviews, vol. 41, no. 1, pp. 1-12, 1996.

[5] D. Eliezer, E. Tal-Gutelmacher, C. E. Cross, and Th. Boellinghaus, "Hydrogen absorption and desorption in a duplex-annealed Ti-6Al-4V alloy during exposure to different hydrogen-containing environments," Materials Science and Engineering A, vol. 433, no. 1-2, pp. 298-304, 2006.

[6] T. I. Wu and J. C. Wu, "Effects of cathodic charging and subsequent solution treating parameters on the hydrogen redistribution and surface hardening of Ti-6Al-4V alloy," Journal of Alloys and Compounds, vol. 466, no. 1-2, pp. 153-159, 2008.

[7] C. B. Zhang, Q. Kang, Z. H. Lai, and R. Ji, "The microstructural modification, lattice defects and mechanical properties of hydrogenated/dehydrogenated $\alpha$-Ti," Acta Materialia, vol. 44, no. 3, pp. 1077-1084, 1996.

[8] Y. Zhang and S. Q. Zhang, "Hydrogenation characteristics of Ti-6Al-4V cast alloy and its microstructural modification by hydrogen treatment," International Journal of Hydrogen Energy, vol. 22, no. 2-3, pp. 161-168, 1997.

[9] H. Yoshimura, "Mezzoscopic grain refinement and improved mechanical properties of titanium materials by hydrogen treatments," International Journal of Hydrogen Energy, vol. 22, no. 2-3, pp. 145-150, 1997.

[10] O. N. Senkov and F. H. Froes, "Thermohydrogen processing of titanium alloys," International Journal of Hydrogen Energy, vol. 24, no. 6, pp. 565-576, 1999.

[11] J. C. Wu and T. I. Wu, "Influences of the cyclic electrolytic hydrogenation and subsequent solution treatment on the hydrogen absorption and evolution of $\beta$-solution treated Ti6Al-4V alloy," International Journal of Hydrogen Energy, vol. 33, no. 20, pp. 5651-5660, 2008.

[12] C. T. Liu, T. I. Wu, and J. K. Wu, "Formation of nanocrystalline structure of Ti-6Al-4V alloy by cyclic hydrogenationdehydrogenation treatment," Materials Chemistry and Physics, vol. 110, no. 2-3, pp. 440-444, 2008.
[13] T. Furuhara, "Role of defects on microstructure development of beta titanium alloys," Metals and Materials International, vol. 6, no. 3, pp. 221-224, 2000.

[14] R. W. Schutz and L. C. Covington, "Effect of oxide films on the corrosion resistance of titanium," Corrosion, vol. 37, no. 10, pp. 585-591, 1981.

[15] T. I. Wu, C. T. Liu, and J. K. Wu, "Use of thiourea to inhibit the incorporation of hydrogen in Ti and Ti-6Al-4V alloy," Materials Letters, vol. 30, no. 5-6, pp. 377-383, 1997.

[16] T. I. Wu and J. K. Wu, "The effects of chemical additives on the hydrogen uptake behavior of Ti-6Al-4V alloy," Materials Chemistry and Physics, vol. 80, no. 1, pp. 150-156, 2003.

[17] B. D. Cullity, Elements of X-Ray Diffraction, Addison-Wesley, Reading, Mass, USA, 2nd edition, 1978.

[18] C.-H. Liao, Effects of cyclic hydrogenation and subsequent solution treatment on the hydrogen distribution of MA and BST CP-Ti [M.S. thesis], Tatung University, Taipei, Taiwan, 2009.

[19] J. W. Zhao, H. Ding, Y. R. Zhong, and C. S. Lee, "Effect of thermo hydrogen treatment on lattice defects and microstructure refinement of Ti6Al4V alloy," International Journal of Hydrogen Energy, vol. 35, no. 12, pp. 6448-6454, 2010.

[20] W. J. He, S. H. Zhang, H. W. Song, and M. Cheng, "Hydrogeninduced hardening and softening of a beta-titanium alloy," Scripta Materialia, vol. 61, no. 1, pp. 16-19, 2009. 

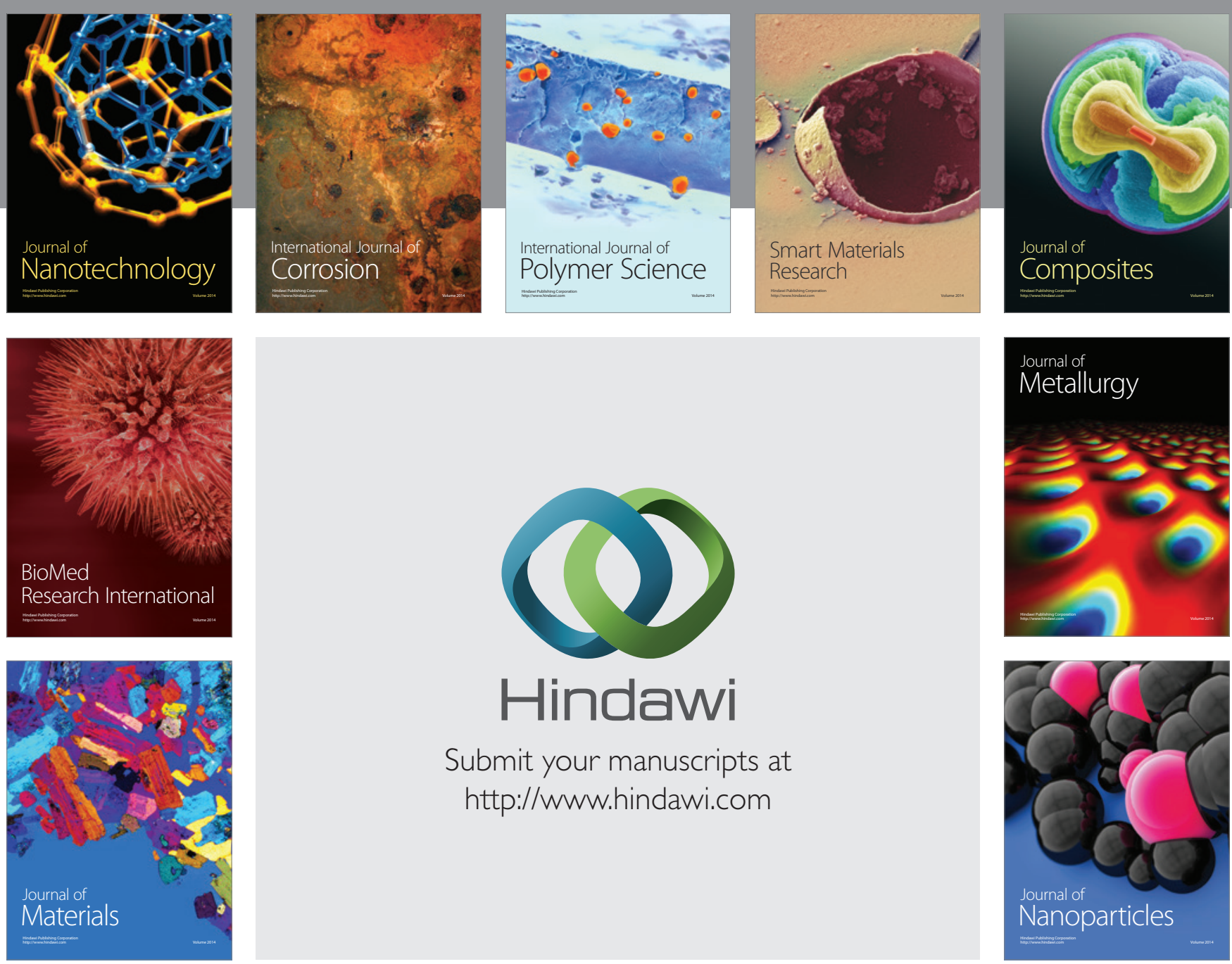

Submit your manuscripts at http://www.hindawi.com
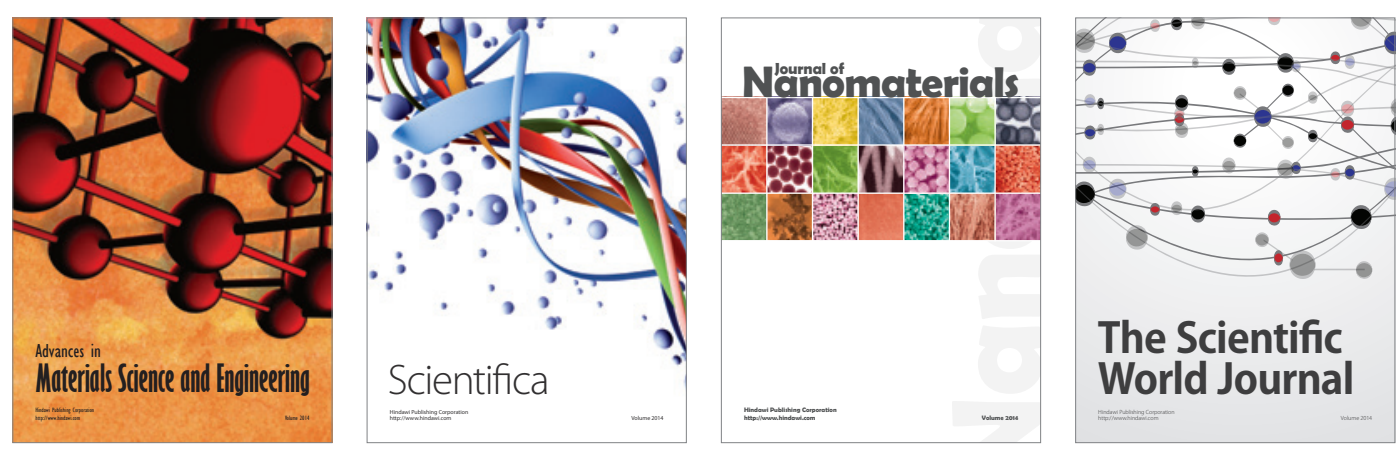

\section{The Scientific World Journal}
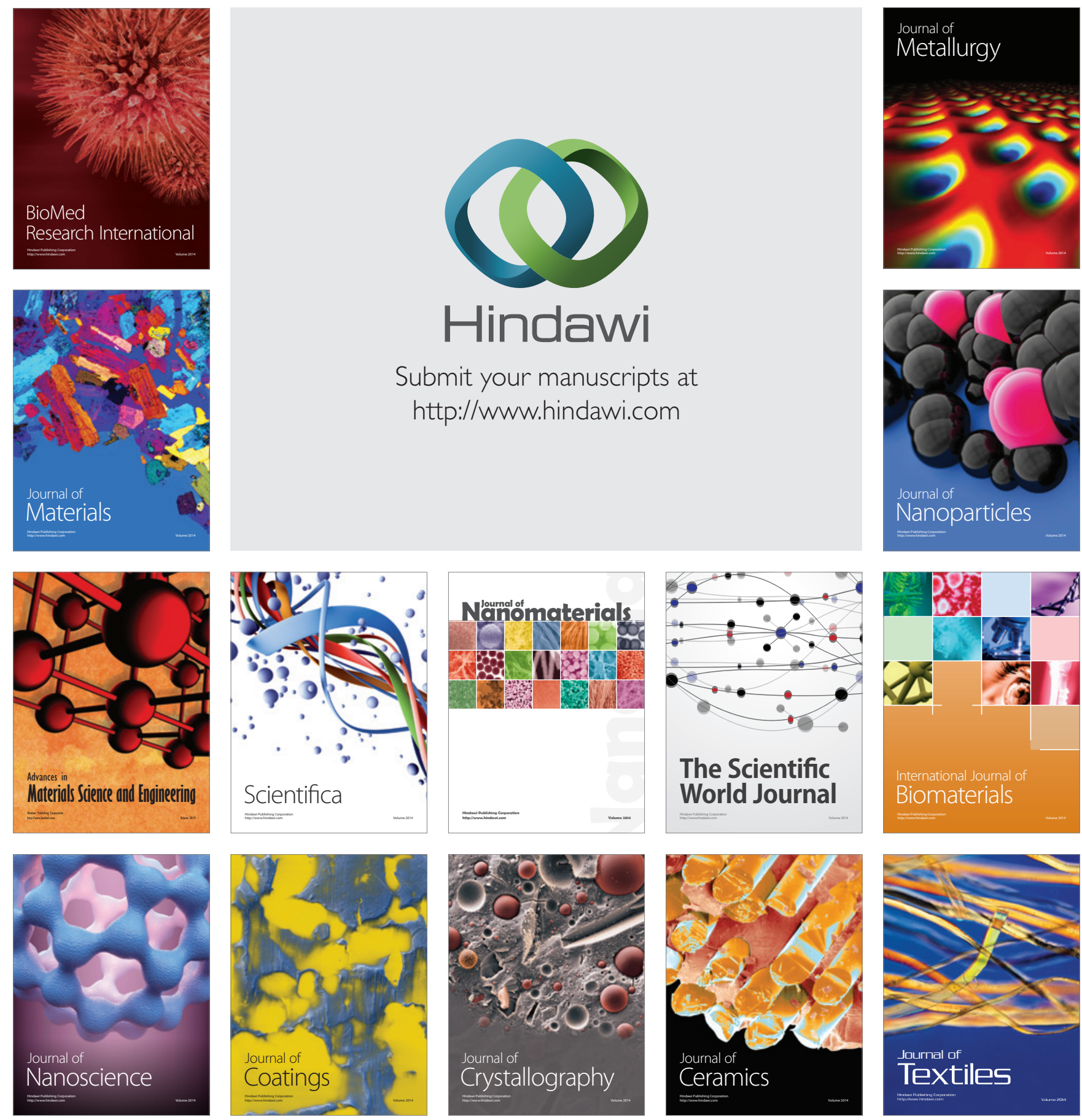